\title{
Thermal tolerance of larval stages of the Chilean kelp crab Taliepus dentatus
}

\author{
Daniela Storch ${ }^{1,2, *}$, Miriam Fernández ${ }^{1}$, Sergio A. Navarrete ${ }^{1}$, Hans-Otto Pörtner ${ }^{2}$ \\ ${ }^{1}$ Estación Costera de Investigaciones Marinas and Center for Advanced Studies in Ecology and Biodiversity, \\ Departamento de Ecología, Facultad de Ciencias Biológicas, Pontificia Universidad Católica de Chile, Casilla 114-D, \\ Santiago, Chile \\ ${ }^{2}$ Alfred-Wegener-Institut für Polar- und Meeresforschung, Integrative Ecophysiology, Postfach 120161, 27515 Bremerhaven, \\ Germany
}

\begin{abstract}
Physiological responses of larval stages can differ from those of the adults, affecting key ecological processes. Therefore, developing a mechanistic understanding of larval responses to environmental conditions is essential vis-à-vis climate change. We studied the thermal tolerance windows, defined by lower and upper pejus (Tp) and critical temperatures (Tc), of zoea I, II, and megalopa stages of the Chilean kelp crab Taliepus dentatus. Tp limits determine the temperature range where aerobic scope is maximal and functioning of the organism is unrestrained, and were estimated from direct observations of larval activity. Tc limits define the transition from aerobic to anaerobic metabolism, and were estimated from the relationship between standard metabolic rate and temperature. Zoea I showed the broadest, zoea II an intermediate, and megalopae the narrowest tolerance window (Tp). Optimum performance in megalopae was limited to Tp between 11 and $15^{\circ} \mathrm{C}$, while their Tc ranged between 7 and $19^{\circ} \mathrm{C}$. Although Tc may be seldom encountered by larvae, the narrower Tp temperatures can frequently expose larvae to unfavorable conditions that can drastically constrain their performance. Temperatures beyond the Tp range of megalopae have been observed in most spring and summer months in central Chile, and can have important consequences for larval swimming performance and impair their ability to avoid predators or settle successfully. Besides the well-documented effects of temperature on development time, variability in field temperatures beyond Tp can affect performance of particular larval stages, which could drive large-scale variability in recruitment and population dynamics of $T$. dentatus and possibly other invertebrate species.
\end{abstract}

KEY WORDS: Metabolic rate - Critical temperature ' Heart beat rate - Larvae ' Megalopa · Sea surface temperature $\cdot$ Recruitment $\cdot$ Zoea

Resale or republication not permitted without written consent of the publisher

\section{INTRODUCTION}

Larval performance is crucial for successful recruitment to the adult habitat and, thus, for abundance and dynamics of populations of benthic marine species with obligate planktonic development. Since survival in the plankton influences the arrival of recruits to adult populations, there is great interest in furthering our understanding of the physiology and ecology of early life history stages to improve management and conservation programs (Rumrill 1990, Morgan 1995). Factors such as temperature, food availability and quality, and predation can largely affect development and survival of larvae, their dispersal from the population of origin, and their chances of successfully completing metamorphosis after returning to shore (Thorson 1950, Pechenik 1987, Morgan 1995, Epifanio \& Garvine 2001, Vargas et al. 2006a,b, Emlet \& Sadro 2006, O'Connor et al. 2007). Sea temperature is probably the most important of these factors, as it influences all physiological and ecological processes of aquatic invertebrates and their life stages (Blaxter 1991, Somero 2002, O'Connor et al. 2007, Pörtner \& Farrell 2008). 
Temperature tolerances of aquatic invertebrates are closely associated with the thermal regime of their environment (Thorson 1950, Morgan 1995, Anger 2001, Pörtner 2001). When trying to infer distribution patterns of species or predict responses to climatic change, most studies have focused on thermal tolerance windows of adult individuals (e.g. Read \& Cumming 1967, Goss \& Bunting 1976, Huey \& Kingsolver 1989, Frederich \& Pörtner 2000, Stillman 2002, Lee 2003, Fangue et al. 2006, Compton et al. 2007, Wittmann et al. 2008), though thermal tolerances may vary greatly across life stages (Jensen et al. 1969, Johnston \& Benett 1996, Anger 2001). Empirical evidence of ontogenetic changes in thermal tolerances has been found in terrestrial lizards, frogs, or air-breathing freshwater snails (Kuramoto 1978, Boon-Niermeijer \& van de Scheur 1984, Xu \& Ji 2006). Surprisingly, thermal tolerance only recently has been shown to vary through developmental stages of marine invertebrates (Anger et al. 2003, Parker et al. 2009, Weiss et al. 2010). Varying thermal sensitivity through developmental stages can have important consequences on population dynamics and can set biogeographic limits to species. Developing a mechanistic understanding of ecological and physiological responses of these larval stages is therefore essential to predict species responses to changing environmental conditions (Vernberg \& Vernberg 1964), particularly under the current global climate change (Pörtner \& Knust 2007).

Two thermal tolerance windows of marine organisms have been defined based on the stepwise limitation/ failure of oxygen supply by ventilatory and circulatory systems (Pörtner 2001, Mark et al. 2002). The narrower tolerance window is set by the upper and lower pejus temperatures $(\mathrm{Tp}$; pejus = getting worse), i.e. the range where aerobic scope (defined as the increase in oxygen consumption from resting to maximal metabolic rates) and functioning of the organism are not limited by oxygen supply (e.g. Frederich \& Pörtner 2000, Peck et al. 2004, Wang \& Overgaard 2007). Critical functions such as activity and growth become constrained beyond the upper and lower Tp (Peck et al. 2004, Pörtner \& Knust 2007). Furthermore, the capacity of circulatory and ventilatory mechanisms is progressively reduced (Frederich \& Pörtner 2000). Upon further cooling or warming, the organisms reach the low or high critical temperature thresholds (Tc), which set the second, broader thermal tolerance window. At this stage, aerobic scope vanishes and the organism's transition into anaerobic metabolism is associated with limitations to supply oxygen to the cells (Pörtner et al. 2005). Within this passive thermal envelope bordered by Tc limits, heart beat and standard metabolic rates (SMR) of resting, non-feeding individuals typically increase exponentially with rising temperature (Pörtner et al.
2005, Wittmann et al. 2008). Beyond the Tc limits, oxygen deficiency and associated disturbances in acidbase and energy status elicit metabolic depression, which becomes clear as a decrease in SMR and is typically correlated with the release of anaerobic endproducts (Melzner et al. 2006).

This conceptual framework of thermal tolerances in which narrow Tp limits are nested within broader Tc limits has so far only been tested in adult specimens of various species from different phyla (Frederich \& Pörtner 2000, Melzner et al. 2006, Pörtner \& Knust 2007, Wittmann et al. 2008, Frederich et al. 2009). Recently it was also applied to the zoea I larvae of the Chilean kelp crab Taliepus dentatus to demonstrate their capacity to adapt to different environmental temperature regimes (Storch et al. 2009). That study demonstrated the applicability of the concept of oxygen and capacity-limited thermal tolerance and the feasibility of defining hierarchical tolerances to temperature using organismal integrative variables, such as behavior. These organismal responses are generally more sensitive to temperature fluctuations than physiological responses (oxygen consumption and heart beat). Here, we use this framework to extend this approach and evaluate its applicability to all larval stages of this crab species, testing the null hypotheses that oxygen and capacity limitations do not vary among larval stages and the idea that some larval stages can often face sub-optimal environmental conditions during their development in the coastal ocean. This is an important step toward a comprehensive understanding of the role of physiological tolerances in performance of invertebrates with complex life cycles, and a critical piece of information to identify bottlenecks of climate sensibility.

The kelp crab Taliepus dentatus is a widely distributed and common species in nearshore rocky habitats along the Peruvian and Chilean coasts. Like in all majids, the planktotrophic development includes 2 zoea and 1 megalopa stages (Fagetti \& Campodonico 1971). In order to identify the larval stage with the narrowest thermal window, we compared thermal responses among the 3 larval stages, characterizing (1) active metabolic rate (AMR), (2) heart beat rate, and (3) larval activity. Using larval activity, a measure of swimming performance, we identified differences in the pejus range between the stages. For the larval stage with the narrowest $\mathrm{Tp}$ window, we estimated the lower and upper Tc by determining the relationship between SMR and temperature. Our results provide insight into how physiological constraints might critically influence larval performance over temperature ranges much narrower than those traditionally considered to indicate physiological failure. We used high frequency sea surface temperature (SST) records to 
show that larval stages have frequently faced Tp limits and sometimes even the Tc limits in the costal ocean. We then discuss the potential effects on larval survival and onshore delivery.

\section{MATERIALS AND METHODS}

Larval culture. SSTs at the collection site in Las Cruces $\left(33^{\circ} 29^{\prime} \mathrm{S}, 71^{\circ} 38^{\prime} \mathrm{W}\right)$ were recorded between February 2001 and March 2008 at 5 min intervals using temperature loggers (Onset tidbit) deployed at $1 \mathrm{~m}$ depth on the shore. Extreme SST values ranged from $10.0^{\circ} \mathrm{C}$ in September 2001 to $21.3^{\circ} \mathrm{C}$ in January 2007 , with a long-term SST mean of $15.6^{\circ} \mathrm{C}$. Therefore, the maintenance and rearing temperatures were set at $15^{\circ} \mathrm{C}$. Ovigerous females of Taliepus dentatus were collected from Las Cruces by local professional divers between February and August 2005. Females were brought to the Estación Costera de Investigaciones Marinas (ECIM) laboratories where all experiments were conducted. Females were maintained individually in 501 aquaria with running seawater at $15^{\circ} \mathrm{C}$, 34 PSU, and a 12:12 h light:dark photoperiod and monitored daily until ready to spawn. Larval hatching and rearing was conducted in a constant temperature room at $15^{\circ} \mathrm{C}$ using the same photoperiod. Newly hatched larvae were collected, and 20 zoea I larvae from each female were transferred to 0.51 culture vessels. The density was reduced to 10 individuals of zoea II and 4 individuals of megalopa stages in $0.5 \mathrm{l}$ as they molted to the successive larval stages. Culture water was changed every $24 \mathrm{~h}$ by transferring all individuals to clean culture bowls containing UV filtered, wellaerated seawater and freshly hatched Artemia. Bowls were checked daily for larval mortality and molts. Under these conditions, at least $50 \%$ of the larvae molted to the megalopa stage in 24 to $27 \mathrm{~d}$ after hatching. The experiments described below were conducted using 5 to $6 \mathrm{~d}$ old zoea I, 17 to $18 \mathrm{~d}$ old zoea II (corresponding to the middle of the respective zoea stages) and 32 to 36 d old megalopa larvae because thermal tolerance might change with development time within a given stage. Larvae were starved $1 \mathrm{~d}$ prior to experiments to provide uniform experimental conditions and to avoid elevated metabolic rates due to specific dynamic action.

The experiments started at the rearing temperature of $15^{\circ} \mathrm{C}$. Immediately after measurements at this temperature, we increased or decreased it to the next experimental temperature at a rate of $4^{\circ} \mathrm{C}$ every $2 \mathrm{~h}$. These temperature steps were chosen because at the central coast of Chile, diurnal temperature fluctuations of $4^{\circ} \mathrm{C}$ are common during summer when larvae are in the water (Kaplan et al. 2003). Moreover, at this same site, SSTs occasionally may vary between 2 and $4{ }^{\circ} \mathrm{C}$ within 1 or $2 \mathrm{~h}$ associated with internal wave activity (Vargas et al. 2004). Experimental temperatures were set at $3,7,11,15,19,23$, and $27^{\circ} \mathrm{C}$. At least 5 larvae from different females were used for each condition and stage. For each stage we also used different females corresponding to 15 different females for the 3 stages. At each experimental temperature, we measured (1) oxygen consumption rate, (2) heart beat rate, and (3) larval activity.

Oxygen consumption. Oxygen consumption rates were measured in individual larvae using Hamilton microliter precision syringes (volume $500 \mu \mathrm{l}$ ) as closed respiration chambers. Oxygen partial pressures in the respiration chamber were recorded by oxygen microoptodes (needle-type fiber-optic micro sensor with flat broken tip, diameter: $140 \mu \mathrm{m}$ ) connected to a Microx TX2 (PreSens). Syringes were placed upside down in a temperature controlled seawater bath containing airsaturated, filtered $(0.45 \mu \mathrm{m}$ filter) seawater (salinity $34 \mathrm{psu}$ ). The needle of the microsensor was inserted from the side of the cannula. Prior to insertion, optodes were calibrated in the same temperature controlled seawater bath where measurements took place. Larvae were carefully introduced into the barrel by removing the plunger. After larvae were placed in the syringe, the plunger was inserted and carefully brought to the desired volume of $40 \mu \mathrm{l}$ for zoea I and $50 \mu \mathrm{l}$ for zoea II and megalopa. The procedure was carried out entirely underwater to avoid introducing air bubbles. Subsequently, the optode was inserted and the sensitive tip was positioned in the middle of the respiration chamber, where larvae could swim freely. During the experimental trials, oxygen depletion was limited to a maximum of $20 \%$. Maintaining oxygen levels above $80 \%$ air saturation minimizes effects on thermal tolerance. In order to correct for bacterial oxygen consumption, blanks were run before and after experimental measurements. At the end of the experiments, larvae were removed from the chambers, carefully dried with a paper towel and weighed on a Sartorius BP $211 \mathrm{D}$ high-precision balance. In this manner, measured oxygen consumptions represent AMR (= SMR + other metabolic costs including the costs of swimming activity). Oxygen consumption rates were expressed as ( $\mu \mathrm{g} \mathrm{O}_{2} \mathrm{~h}^{-1}$ ind. $^{-1}$ ) when estimating the costs of swimming and SMRs of megalopa stages. To compare mean oxygen consumption rates among the 3 larval stages, we divided oxygen consumption by larval fresh weight $\left(\mu \mathrm{g} \mathrm{O} \mathrm{Omg}^{-1} \mathrm{FW} \mathrm{h}^{-1}\right)$.

Heart beat rate. Heart beat rate was recorded with a video flex camera mounted onto a binocular microscope with bottom-up light and connected to a timelapse video recorder. Larvae were placed under the scope in a temperature-controlled micro-chamber 
filled with seawater, which allowed changing the temperature according to the experimental protocol without disturbing the larvae. The larva was positioned in the center of the micro-chamber by gluing the carapace to a thin glass spine, which itself was attached to a glass table, using rapid glue. Thus, larvae freely flapped abdomen, pleopods, and maxillipeds in the experimental glass chamber enclosed by aluminum foil to avoid visual disturbance. Larvae were left for $1 \mathrm{~h}$ at $15^{\circ} \mathrm{C}$ to recover from handling stress and were videotaped for $4 \mathrm{~min}$. After this period, temperature was changed according to the protocol described above, and at each experimental temperature the larvae were videotaped for $4 \mathrm{~min}$. The beating heart can easily be seen through the transparent carapace. The number of contractions per unit time was counted by playing the videotape in slow motion. Heart rate was calculated for each larva as the mean number of beats $\mathrm{min}^{-1}$ from the same six $10 \mathrm{~s}$ intervals as for maxilliped or pleopod beating (see below).

Larval activity. Zoeal maxilliped and abdomen and megalopae pleopod beat rates were determined using the same video sequences as for analysis of the heart beat rate described above. Maxilliped or pleopod beating was calculated as the mean number of beats $\mathrm{min}^{-1}$ from six $10 \mathrm{~s}$ intervals. Abdomen beating was calculated according to Storch et al. (2009).

Costs of pleopod beating and SMR. An independent set of experiments was conducted only on the megalopa stage at the experimental temperature of $15^{\circ} \mathrm{C}$ to determine the metabolic cost of pleopod beating. Using this data set, the AMR, per individual, of the thermal tolerance experiment was corrected for the costs of pleopod beating to obtain the temperature-dependent SMR. Due to the difficulty to measure AMR and pleopod beating at the same time in the same megalopa, AMR and pleopod beating were measured in different larvae, and then we statistically related beating rates to oxygen consumption using model fitting. In total, 110 megalopa larvae were used: 55 to estimate AMRs and 55 to determine pleopod beat rates. A large sample size was needed to cover a wide range of AMRs and pleopod beat rates.

Statistical analyses. Separate 2-way analyses of variance (ANOVAs) were conducted to test for the effect of larval stage (fixed factor) and temperature (fixed factor) on weight specific oxygen consumption and heart rate. In the case of activity variables, we conducted separate analyses, since zoea use their maxillipeds and abdomen for swimming but megalopa use the maxillipeds for feeding and the pleopods (connected to the abdomen) for swimming. (1) To compare maxilliped and abdomen beat rates between the 2 zoea stages and among all tempera- tures, we used 2 separate 2-way ANOVAs. (2) We used a 1-way ANOVA to compare megalopa pleopod beat rates among the experimental temperatures. Whenever the interaction between factors was significant, we used simple main effect tests (Quinn \& Keough 2002) using the 'Slice' option in SAS to determine main effects of larval stage at each experimental temperature, followed by Bonferroni adjustment of probabilities (Quinn \& Keough 2002). In addition, a posteriori Tukey-Kramer tests were run when significant differences among temperature treatments were detected, separately for each larval stage.

To estimate the costs of pleopod beating, we fitted various linear and non-linear (quadratic, cubic) models to AMR and pleopod beating rate data. The best model was selected using the Akaike Information Criterion (AIC). Assuming that (1) AMR rises with increasing pleopod beating and (2) the costs of pleopod beating do not change with temperature (see 'Discussion'), the aerobic cost of pleopod beating was estimated for each temperature and subtracted from the observed AMR measured at that temperature.

\section{RESULTS}

\section{Oxygen consumption}

Oxygen consumption (AMR) varied greatly with experimental temperature, but in different ways for the 3 different larval stages (Fig. 1). While a fairly smooth increase in AMR with temperature were observed in zoea I (Fig. 1A), except for a slight increase at $7^{\circ} \mathrm{C}$, clear unimodal trends were observed in zoea II and megalopa stages (Fig. 1B,C). Consequently, the 2-way ANOVA showed a highly significant interaction between temperature and larval stage (Table 1). Simple main effect tests (Bonferroni adjusted) showed that oxygen consumption (AMR) of the 3 larval stages differed significantly at 23 and $27^{\circ} \mathrm{C}$, and was similar at all other experimental temperatures. A posteriori Tukey tests within each larval stage showed that oxygen consumption (AMR) was higher at 23 and $27^{\circ} \mathrm{C}$ for zoea I than at most other temperatures (Fig. 1A). In contrast, oxygen consumption (AMR) of zoea II at $27^{\circ} \mathrm{C}$ showed a sharp decrease, reaching similar low levels to those observed at $3^{\circ} \mathrm{C}$ (Fig. 1B). Similarly, oxygen consumption (AMR) of megalopa at $27^{\circ} \mathrm{C}$ was low and similar to that observed at $3^{\circ} \mathrm{C}$, but in this case, the sharp decrease in oxygen consumption (AMR) was already observed at $23^{\circ} \mathrm{C}$ (Fig. 1C). Thus, limits to temperature tolerance were apparent first in megalopa then in zoea II, and were not detectable in zoea I within the range of experimental temperatures. 


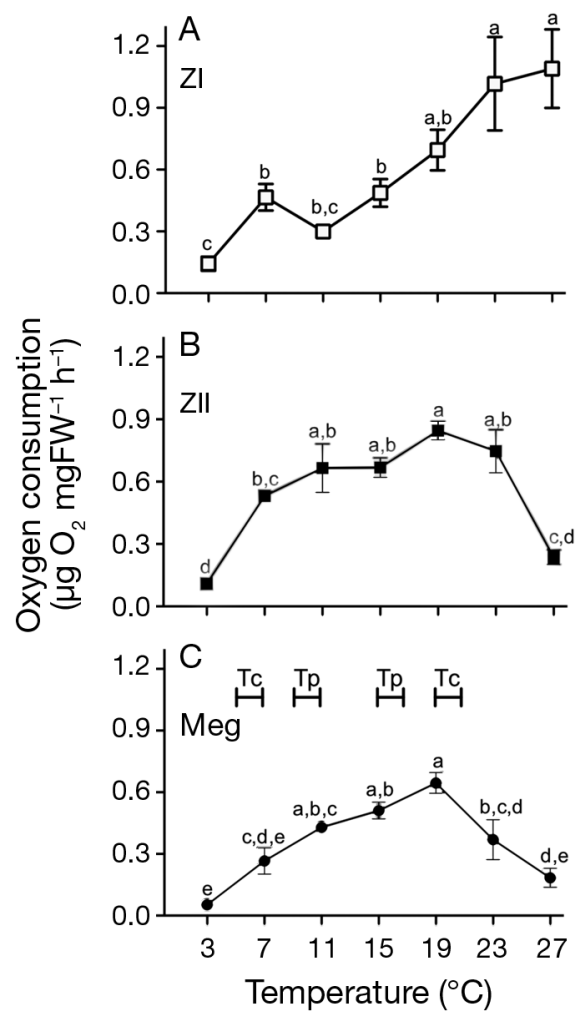

Fig. 1. Taliepus dentatus. Effect of acute temperature changes on active metabolic rate of (A) zoea I (ZI), (B) zoea II (ZII), and (C) megalopa (Meg) from central Chile. Means $\pm \mathrm{SE}, \mathrm{n}=5$. Different letters indicate significant differences with $\mathrm{p}<0.05$. $\mathrm{Tp}$ : lower and upper pejus temperature limits; Tc: lower and upper critical temperatures of megalopae (Tp derived from Fig. 3E and Tc derived from Fig. 5), which are given as ranges (horizontal bars)

\section{Heart beat}

Larval heart beat rates were strongly modified by experimental temperatures, but in different ways among the 3 larval stages, rendering a significant 'temperature $\times$ larval stage' interaction in the 2-way ANOVA (Table 1). A steady increase in heartbeat rates with increasing experimental temperature was observed in zoea I and megalopae (Fig. 2A,C), but a sharp drop in heartbeat rate at the highest temperature was apparent for zoea II (Fig. 2B). Consequently, single main effect tests (Bonferroni adjusted) showed that the 3 stages differed only at $27^{\circ} \mathrm{C}$ and were similar at all other temperatures. The standard error (SE) for heart beat rate in zoea II at $27^{\circ} \mathrm{C}$ was higher than at other temperatures because 1 larva died at this experimental temperature. A posteriori Tukey tests for each larval stage also showed patterns consistent with increasing heart beat rate with temperature, except for the zoea II stage at $27^{\circ} \mathrm{C}$. Thus, thermal limitation of heart beat rate was only detected at the highest temperature of $27^{\circ} \mathrm{C}$ and only for the zoea II stage.

\section{Larval activity}

Larval activity was significantly affected by temperature in all larval stages (Fig. 3) even though there was high variation among replicate larvae, resulting in high SEs for each treatment (Fig. 3). Consistent effects of temperature on maxilliped beating were observed between the 2 zoea stages (Table 1, non-significant interaction between temperature and larval stage). No differences in mean maxilliped beating rates were observed between the 2 zoea stages (Table 1), while experimental temperature had a significant effect (Table 1). A posteriori Tukey tests showed that in both zoea stages, maxilliped beating rates decreased sharply upon cooling from $7^{\circ}$ to $3^{\circ} \mathrm{C}$ and also decreased at higher temperatures $\left(>19^{\circ} \mathrm{C}\right.$; Fig. $\left.3 \mathrm{~A}, \mathrm{~B}\right)$.

The influence of temperature was less pronounced on abdominal beat rates than on maxilliped beat rates (Fig. 3C,D), but it was still significant (Table 1) and it was consistent between the 2 zoea stages (Table 1, no significant interaction). Significantly lower abdomen beat rates were observed at $3^{\circ} \mathrm{C}$ (Tukey test, $\mathrm{p}<0.05$ ), remaining constant with increasing temperatures. Moreover, average abdomen beat rates were signifi-

Table 1. Taliepus dentatus. Results of analysis of variance conducted to assess the effect of temperature and larval stage on active metabolic rate and heart beat between the 3 larval stages, maxilliped and abdomen beat rates in the zoea stages and to assess the effect of temperature on pleopod beat rate of megalopae

\begin{tabular}{|lcrrc|}
\hline $\begin{array}{l}\text { Response } \\
\text { variable }\end{array}$ & $\begin{array}{c}\text { Source of } \\
\text { variation }\end{array}$ & df & $F$ & $\mathrm{p}$ \\
\hline Active & Temperature $(\mathrm{T})$ & 6 & 17.47 & $<0.0001$ \\
metabolic & Stage $(\mathrm{S})$ & 2 & 15.55 & $<0.0001$ \\
rate & $\mathrm{T} \times \mathrm{S}$ & 12 & 7.05 & $<0.0001$ \\
& Error & 84 & & \\
Heart beat & $\mathrm{T}$ & 6 & 80.27 & $<0.0001$ \\
rate & $\mathrm{S}$ & 2 & 6.37 & 0.0026 \\
& $\mathrm{~T} \times \mathrm{S}$ & 12 & 5.27 & $<0.0001$ \\
Maxilliped & Error & 84 & & \\
beat rate & $\mathrm{T}$ & 6 & 14.61 & $<0.0001$ \\
& $\mathrm{~S}$ & 1 & 0.03 & 0.86 \\
Abdomen & $\mathrm{T} \times \mathrm{S}$ & 6 & 1.45 & 0.21 \\
beat rate & Error & 57 & & \\
& $\mathrm{~T}$ & 6 & 5.24 & 0.002 \\
& $\mathrm{~S}$ & 1 & 1.85 & 0.178 \\
Pleopod & $\mathrm{T} \times \mathrm{S}$ & 6 & 1.31 & 0.31 \\
beat rate & Error & 57 & & \\
& $\mathrm{~T}$ & 6 & 12.94 & $<0.0001$ \\
& Error & 28 & & \\
\hline
\end{tabular}




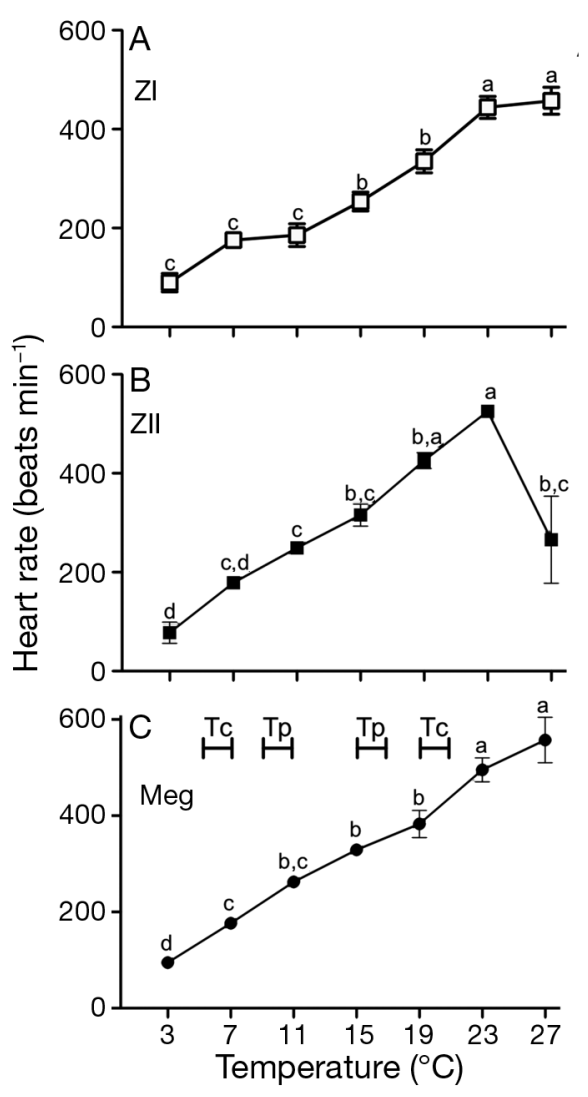

Fig. 2. Taliepus dentatus. Effect of acute temperature changes on heart beat rate of actively swimming (A) zoea I (ZI), (B) zoea II (ZII), and (C) megalopa (Meg) from central Chile. Means $\pm \mathrm{SE}, \mathrm{n}=5$. Different letters indicate significant differences with $p<0.05$. Tp: lower and upper pejus temperature limits; Tc: lower and upper critical temperatures of megalopae (Tp derived from Fig. 3E and Tc derived from Fig. 5), which are given as ranges (horizontal bars)

cantly higher in zoea I than in zoea II (Table 1, Fig. $3 C, D$, note differences in $y$-axis scales).

Pleopod beat rates of megalopae varied greatly among experimental temperatures (Table 1, Fig. 3E). The highest pleopod beat rates were recorded at 11 and $15^{\circ} \mathrm{C}$ (Tukey test, $\mathrm{p}<0.05$ ) indicating the lower and upper $\mathrm{Tp}$ and the temperature range within which megalopa are fully active. Pleopod beat rates were significantly lower at $3,7,19,23$, and $27^{\circ} \mathrm{C}$, which exhibited similar low beating rates $(p>0.05)$. Megalopae were unable to move at $3^{\circ} \mathrm{C}$, but temperatures higher than $15^{\circ} \mathrm{C}$ also induced significant inactivity of megalopae.

\section{Costs of pleopod beating and SMR}

We estimated the costs of pleopod beating to correct for the influence of activity on oxygen consumption and in this manner determine SMR of megalopa larvae. It was not possible to assess these costs on zoea stages. The best fit to the relationship between AMR and pleopod beating (PB) was a third-order polynomial function $\left(\mathrm{AMR}=\right.$ common intercept $+a \mathrm{~PB}^{3}+b \mathrm{~PB}^{2}+$ ${ }_{C} \mathrm{~PB}^{3}$; Fig. 4). According to AIC criteria, the third-order polynomial function was preferable in comparison to the quadratic $(24 \%$ probability, difference in AICc: $-2.3)$, fourth-order polynomial $(<0.01 \%$ probability, difference in AICc: 42.31) and the simple power function $(<0.01 \%$ probability, difference in AICc: 115.73$)$. The coefficients for the third-order polynomial were all significant (Fig. 4): $a=1.0551 \times 10^{-14}(\mathrm{p}<0.001), b=$ $-4.8791 \times 10^{-10}(\mathrm{p}<0.001), c=8.6290 \times 10^{-6}(\mathrm{p}<0.05)$, with common intercept $=0.5511(\mathrm{p}<0.001), \mathrm{R}^{2}=0.98$.

Using the observed pleopod beat rates at different temperatures, we estimated that the highest metabolic costs associated with pleopod beating occurred at 11 and $15^{\circ} \mathrm{C}$. At these experimental temperatures, pleopod beating costs were $22 \pm 5 \%$ and $17 \pm 7 \%$ of total AMR, respectively. Beyond these temperatures, beating costs accounted for between $0 \pm 0 \%$ and $7 \pm 2 \%$ of the AMR. Correcting the approximately linear response of AMR to temperature by the estimated costs of pleopod beating yielded an approximately exponential SMR response to temperature in the range from 7 to $19^{\circ} \mathrm{C}$. The exponential model for SMR was preferable in comparison to the linear response within this temperature range $\left(7\right.$ to $19^{\circ} \mathrm{C}, 82.44 \%$ probability of the exponential function to be correct; difference in AICc: 3.09). Similar to the AMR, SMRs decreased sharply between 7 and $3^{\circ} \mathrm{C}$ and also when temperatures exceeded $19^{\circ} \mathrm{C}$ (Fig. $5 ; \mathrm{p}<0.05$ ), indicating that between 3 and $7^{\circ} \mathrm{C}$ and between 19 and $23^{\circ} \mathrm{C}$ were the upper and lower $\mathrm{Tc}$, respectively.

\section{DISCUSSION}

Differences of pejus ranges between stages and critical temperatures ( $\mathrm{Tc}$ ) for Taliepus dentatus megalopae were identified by applying the integrative physiological concept of thermal tolerance developed for adult individuals (Pörtner et al. 1998, 2005). Recently, this concept of oxygen- and capacity-limited thermal tolerance was successfully applied to zoea I larvae of T. dentatus from populations living at different latitudes that showed persistent differences in thermal adaptation (Storch et al. 2009). Here we extended the analysis to the 3 dispersal larval stages (zoea I, zoea II, and megalopa) and show that the 3 larval stages from the same population display different levels of thermal tolerance and identify the most thermally sensitive stage that might be the bottleneck for species survival and successful recruitment. The optimum temperature 


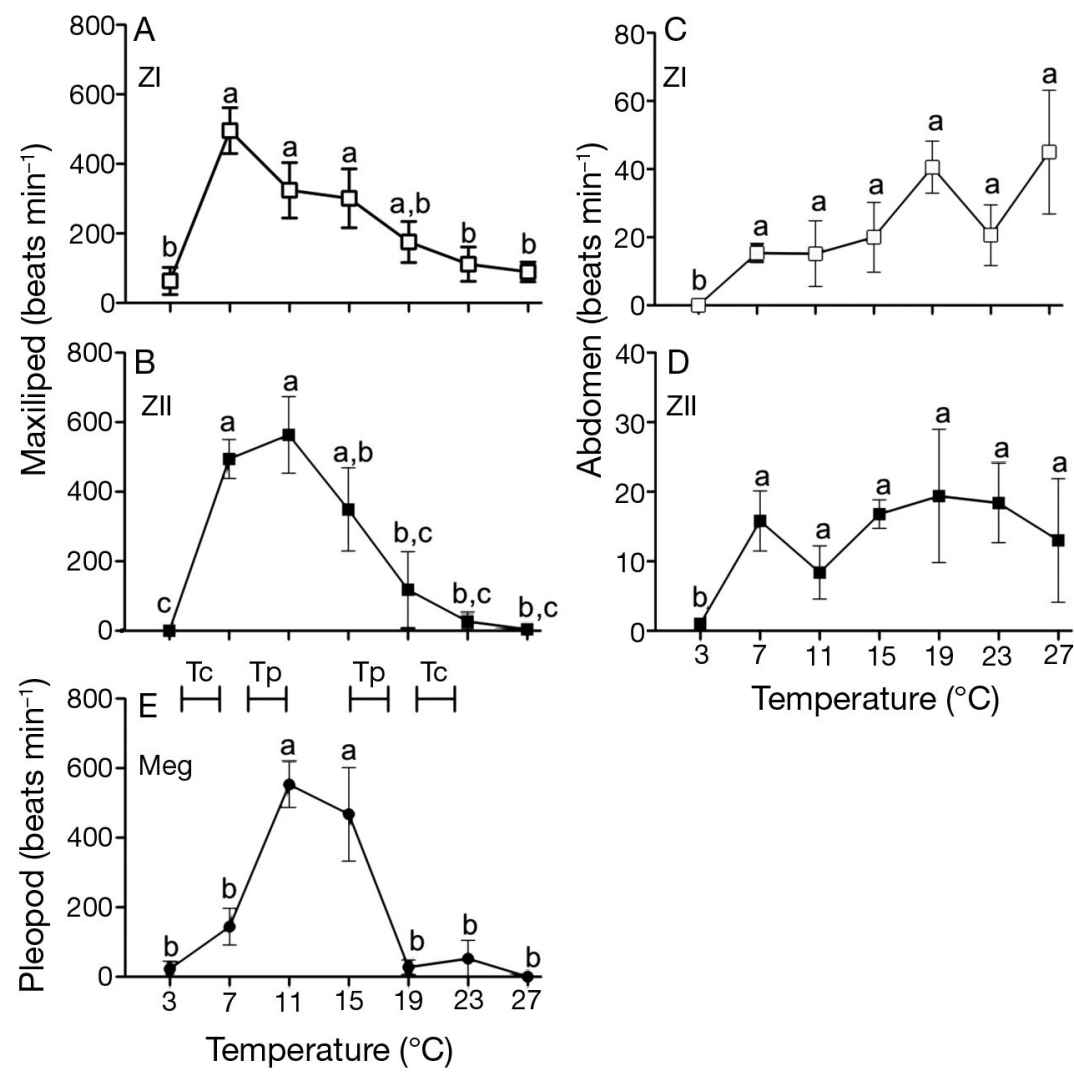

Fig. 3. Taliepus dentatus. Effect of acute temperature changes on maxilliped beat rate of (A) zoea I (ZI) and (B) zoea II (ZII) and abdomen beat rate of (C) zoea I and (D) zoea II (note differences in $y$-axis scales) and pleopod beat rate of (E) megalopa (Meg) from central Chile. Means $\pm \mathrm{SE}, \mathrm{n}=5$. Different letters indicate significant differences with $\mathrm{p}<0.05$. Tp: lower and upper pejus temperature limits, which are given as ranges (horizontal bars); Tc: lower and upper critical temperatures of megalopae (derived from Fig. 5), which are given as ranges (horizontal bars) ranges were broadest in zoea I, intermediate in zoea II and narrowest in the final megalopa larval stage. Furthermore, a shift in maximum swimming activity was observed from colder to warmer temperatures when comparing zoea I and megalopa. The decrease in thermal tolerance limits from zoea I to megalopa was consistent with our AMR data. Since crustaceans undergo ontogenic changes in their cardiovascular functions (e.g. Spicer \& Morritt 1996), we suggest that zoea I might be less dependent on the supply of oxygen through the heart in comparison to the larger megalopa. The megalopa larvae are larger (D. Storch et al. unpubl. data) and more highly developed than the zoea stages and might therefore be more sensitive. The smaller temperature window of the larger megalopa larvae in comparison to smaller zoea is in accordance with the oxygen-limitation model that predicts that temperature-dependent aerobic limits are experienced earlier by larger than by smaller individuals. Thermal sensitivity in activity (exercise), or other variables such as growth, was also found to be enhanced in larger compared with small individuals of various fish species (Linton et al. 1998, Rodnick et al. 2004, Pörtner \& Knust 2007).

Within the broader thermal tolerance window set by the upper and lower $\mathrm{Tc}_{\mathrm{c}}$

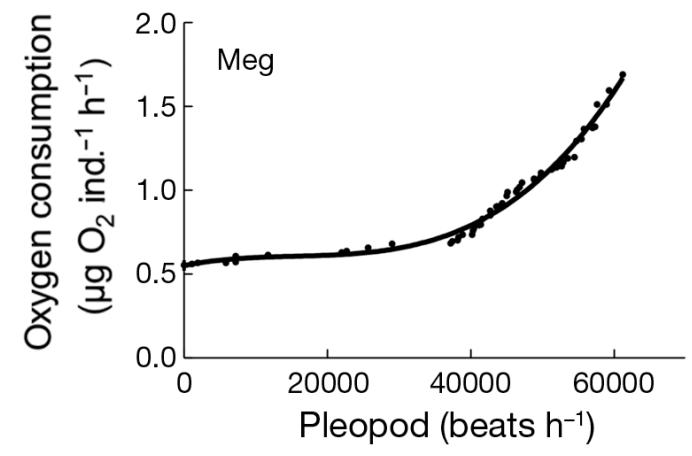

Fig. 4. Taliepus dentatus. Relationship between active metabolic rate (AMR, $\mu \mathrm{g} \mathrm{O}_{2}$ ind. ${ }^{-1} \mathrm{~h}^{-1}$ ) and pleopod beat rate (beats $\mathrm{h}^{-1}$ ) in megalopa (Meg) at $15^{\circ} \mathrm{C}$. The curve fit is a third-order polynomial function

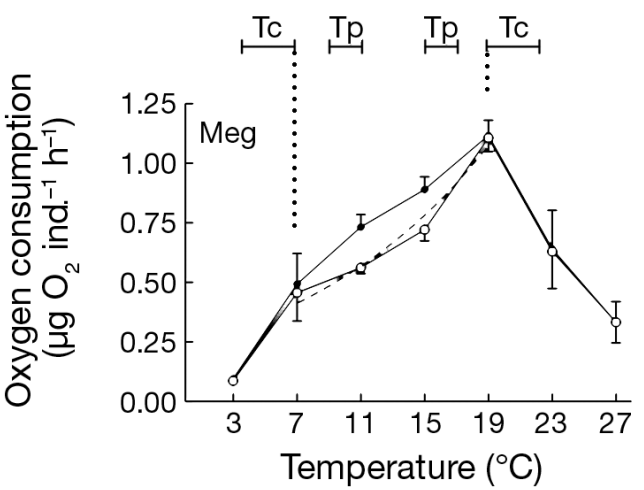

Fig. 5. Taliepus dentatus. Effect of temperature on standard metabolic rate $(\mathrm{SMR}, \mathrm{O})$ in megalopa (Meg) as evaluated from active metabolic rate $(\mathrm{AMR}, \bullet)$ by subtracting the metabolic costs of pleopod beating through the third-order polynomial function depicted in Fig. 4. Means $\pm \mathrm{SE}, \mathrm{n}=5$. The fitted exponential curve progression of SMR between 7 and $19^{\circ} \mathrm{C}$, $y=0.24^{0.08 x}$, is shown as a broken line. Tc indicates the resulting lower and upper critical temperature limits. Tp: lower and upper pejus temperature limits (derived from Fig. 3E) 
heartbeat rates and SMRs of resting, non-feeding animals typically increase exponentially with rising temperature (Pörtner et al. 2000, Melzner et al. 2006, Wittmann et al. 2008). Assuming that the exponential phase of SMR response to temperature is indicative of the window between critical tolerance limits, lower and upper Tc in the megalopae were found at about 7 and $19^{\circ} \mathrm{C}$, respectively. It should be noted that we cannot exactly define temperature limits, which may fall between 2 experimental temperatures, but the overall result that megalopa larvae show the lowest thermal tolerances should remain unchanged.

Higher functions, such as locomotory activity and growth, are first affected when the intracellular capacity to perform aerobically decreases with increasing or decreasing temperature (Peck et al. 2004, Pörtner et al. 2005). In the case of Taliepus dentatus, such a constraint on locomotion became evident at higher temperatures in zoea I and II and $19^{\circ} \mathrm{C}$ or lower in megalopae. Low activity in the zoea stages or cessation of activity in megalopae beyond these temperature limits save aerobic energy for the temperature-dependent increase in maintenance costs, which was paralleled by rising heart beat rates. Our data thus support the concept of hierarchical thermal tolerances. The pattern observed might reflect both the influence of motor activity and the decreasing capacity of the circulatory system to provide oxygen to the organism, for instance because of kinetic limitations in the cold or due to falling oxygen concentrations in the hemolymph (Frederich \& Pörtner 2000). It must be noted that the lower and upper Tp limits of the megalopae are conservatively given as ranges. The $4^{\circ}$ temperature steps used in our experimental design prevented higher precision. Considering the temperature steps and possible ranges, Tp can be set between $8-11^{\circ} \mathrm{C}$ and $15-18^{\circ} \mathrm{C}$ for megalopae. Like the oxygen consumption rates, measures of larval activity indicate that limitation in temperature tolerance becomes apparent first in megalopa.

Since Taliepus dentatus larvae are permanently swimming in the water column, it is impossible to directly measure SMRs or heart beat rate of resting animals (Storch et al. 2009, present study). For an assessment of Tc from temperature-dependent SMR in T. dentatus megalopae, we estimated SMR from measured AMR as carried out by Halcrow \& Boyd (1967). Respiration increases with increasing pleopod beating rate (Torres \& Childress 1983, Swadling et al. 2005). For instance, the costs for locomotor activity in the mysid Euphausia pacifica resulted in a more than 3-fold increase in oxygen consumption (Torres \& Childress 1983), which is comparable to the variation in oxygen consumption we report here for T. dentatus megalopae. Similarly, positive relationships between oxygen consumption and swimming activity or swimming speed have been determined for various aquatic invertebrates and fish, and have been described as semi-logarithmic, linear, quadratic, or third-order polynomial functions (Halcrow \& Boyd 1967, Quetin et al. 1978, Kaufmann 1990, Bartol et al. 2001). In our case, a third-degree polynomial function best described the relationship, suggesting that at very low levels of pleopod beating, oxygen consumption per beat is lower than at intermediate and high beating rates. This relationship allowed us to estimate the metabolic costs of pleopod beating at various incubation temperatures assuming that the costs per beat remain constant regardless of temperature. Such an assumption is supported by studies with other organisms. For instance, in free-swimming cod, the cost of swimming at a given submaximal swimming speed did not change with acclimatization temperature (Claireaux et al. 2006). Clearly, further studies are needed to better determine whether the costs associated with pleopod beating are fully independent of temperature in T. dentatus megalopae, but our preliminary observations suggest that a potential cost increment would not substantially alter the observed response of SMR to temperature.

The effect of temperature on the physiology of Taliepus dentatus larvae can have great ecological implications, if under natural conditions larval stages are faced with temperatures approaching $\mathrm{Tc}_{\mathrm{c}}$ but also when approaching the narrower range set by $\mathrm{Tp}$. Exposure to temperatures outside the Tp range, especially in megalopae, can have large consequences on successful settlement back onshore, since swimming performance can largely modulate physical transport processes in the ocean (Morgan 1995, Shanks 1995).

High-frequency temperature records at the study site indicate that indeed larvae can experience these unfavorable temperatures in the coastal ocean (Fig. 6). In fact, the average minimum and maximum seawater temperatures reported between 2002 and 2008 were $9 \pm 0.6^{\circ} \mathrm{C}$ and $19.8 \pm 1.1^{\circ} \mathrm{C}$, with lowest annual temperatures typically occurring in September/October and highest between December and February (Fig. 6). Ovigerous females of Taliepus dentatus occur year round in central Chile and, except for a short period in winter, hatching takes place during the entire year, although it peaks during the austral spring and summer (Fagetti \& Campodonico 1971, Pardo et al. 2007). Considering that larval development in this species takes weeks to months, we can assume that T. dentatus larvae are exposed to both temperature extremes during the planktonic phase, before they return to the benthos and recruit to the adult populations. Thermal window shifts due to acclimatization might help the larvae to overcome temperature shifts to some extent during their time in the water column (Pörtner \& Far- 


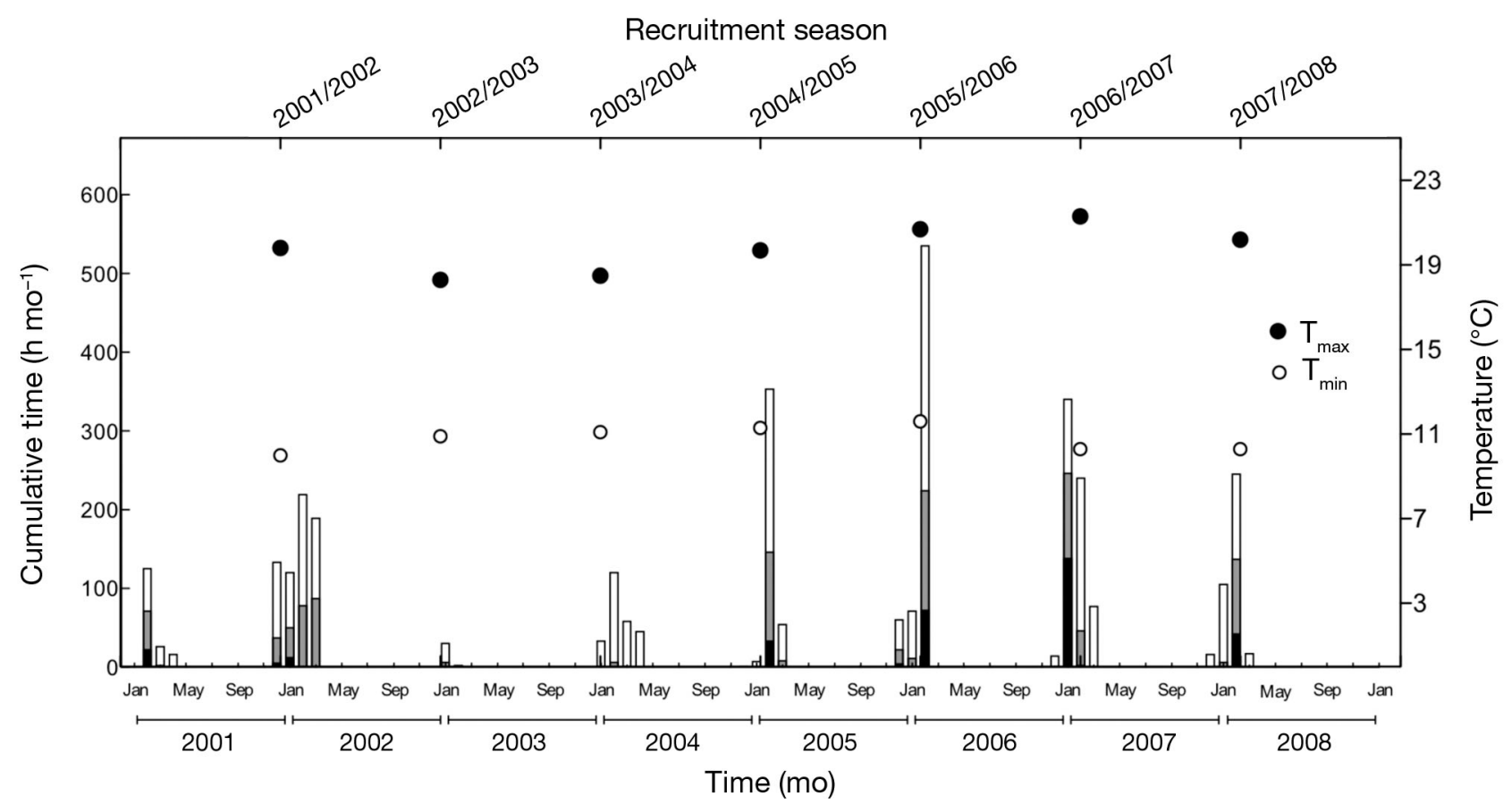

Fig. 6. Cumulative time (h mo ${ }^{-1}$, left $y$-axis) with registered temperatures $\geq 17^{\circ} \mathrm{C}$ (open bars), $\geq 18^{\circ} \mathrm{C}$ (grey bars), and $\geq 19^{\circ} \mathrm{C}(\mathrm{criti}-$ cal temperature, $T c$, black bars) per month (lower $x$-axis) and minimum $\left(\mathrm{T}_{\min }\right.$ : $\left.\bigcirc\right)$ and maximum $\left(\mathrm{T}_{\max }\right.$ : $\bullet$ ) annual temperatures (right $y$-axis) for each larval recruitment season in Las Cruces (upper $x$-axis), central Chile, during 2001 to 2008

rell 2008, Pörtner et al. 2009). However, little is known about the acclimatization capacity of larvae, and this might itself vary among stages. Zoea I of T. dentatus acclimatized at $11^{\circ} \mathrm{C}$ (Storch et al. 2009) compared to zoea I acclimatized at $15^{\circ} \mathrm{C}$ (this study), from the same population, showed only marginal ability to shift their thermal window. This was indicated by a leveling-off in oxygen consumption and heart beat rates in larvae acclimatized at lower temperatures $\left(11^{\circ} \mathrm{C}\right)$ as compared to $15^{\circ} \mathrm{C}$. Acclimatization capacity of megalopa larvae, the thermally most sensitive larval stage of $T$. dentatus, must be explored for a better understanding of its role in larval performance in the face of changing temperatures. However, the shift of the thermal tolerance window between stages despite constant rearing/acclimatization temperatures suggests relatively low acclimatization capacity of these larvae. Since zoea I occur in spring in the water column when seawater temperatures range between 10 and $18^{\circ} \mathrm{C}$, we should expect an optimum performance of megalopa at slightly warmer temperatures because they occur during the warmer summer months.

The narrow optimum temperature range of Taliepus dentatus megalopae and the need to remain within the optimal thermal window and avoid extreme temperatures observed in many crab larvae (e.g. Forward 1990, Boudreau et al. 1991) in order to maintain aerobic metabolism and high swimming activity, emphasizes their degree of thermal specialization. Behavioral responses to temperature can help larvae to control the experienced temperature regime only within limits (Kelly et al. 1982, Sulkin 1984, Forward 1990, Shanks 1995, Gardner et al. 2004), due to the large-scale nature of most physical drivers of SST fluctuations (e.g. upwelling, diurnal heating, internal waves). Larvae are exposed to these fluctuations and are forced to respond physiologically to these thermal regimes. Since temperatures beyond Tp affect swimming performance, we conjecture that interannual variation in temperature regimes and the frequency at which larvae face temperature extremes can be an important source of interannual variation in recruitment success. Temperatures exceeding about $17^{\circ} \mathrm{C}$, which impose a strong constraint on swimming, occur frequently at the study site (Fig. 6). Inability to swim converts megalopae into passive particles, which makes them more vulnerable to predation and starvation and could prevent them from returning to recruitment areas. Highfrequency temperature records for the past $8 \mathrm{yr}$ showed that the lower $\mathrm{Tp}$ of $11^{\circ} \mathrm{C}$ is frequently surpassed (Fig. 6), whereas the lower Tc of $7^{\circ} \mathrm{C}$ has never been observed at the study site. Conversely, the upper Tp corresponds roughly to the long-term mean of SST $\left(15.6^{\circ} \mathrm{C}\right)$, and the upper $\mathrm{Tc}$ values of $19^{\circ} \mathrm{C}$ can be reached or surpassed several times during summer months, but not in all years (Fig. 6). Beyond the upper Tc, larval survival will be limited and mortality will drastically increase with exposure time. 
In conclusion, survival and onshore recruitment of megalopa larvae could be strongly influenced by the frequency of exposure to temperatures beyond the narrow range set by $\mathrm{Tp}$. Such sublethal effects of temperature on larval swimming performance have not been considered in previous studies on temperature effects and the consequences of predicted climate change, which have largely focused on the effects of temperature on larval development rates (e.g. O'Connor et al. 2007) or mortality produced by temperatures beyond Tc. The case study on Taliepus dentatus larvae demonstrates the need to determine optimum physiological thresholds (Tp) for larval stages that must continually swim to survive and to finally recruit into adult habitat. This information must be incorporated into our prediction of the effects of global warming and other large-scale phenomena such as El Niño events.

Acknowledgements. We thank F. Véliz for technical support and K. Cabeza for assistance in larval rearing. Comments by the reviewers were helpful to improve this manuscript. This research was supported by a Feodor Lynen fellowship from the Alexander von Humboldt foundation and DFG project STO 857/1-1 to D.S. M.F. received grants from Fondecyt no. 1060489 and FONDAP-Fondecyt no. 1501-0001. Supplement data are available at doi:10.1594/PANGAEA.760078

\section{LITERATURE CITED}

Anger K (2001) The biology of decapod crustacean larvae. Crustacean issues. AA Balkema Publishers, Lisse

Anger K, Thatje S, Lovrich G, Calcagno J (2003) Larval and early juvenile development of Paralomis granulosa reared at different temperatures: tolerance of cold and food limitation in a lithodid crab from high latitudes. Mar Ecol Prog Ser 253:243-251

Bartol IK, Mann R, Patterson MR (2001) Aerobic respiratory costs of swimming in the negatively buoyant brief squid Lolliguncula brevis. J Exp Biol 204:3639-3653

Blaxter JHS (1991) The effect of temperature on larval fishes. Neth J Zool 42:336-357

Boon-Niermeijer EK, van de Scheur H (1984) Thermosensitivity during embryonic development of Lymnaea stagnalis (Mollusca). J Therm Biol 9:265-269

Boudreau B, Simard Y, Bourget E (1991) Behavioural responses of the planktonic stages of the American lobster Homarus americanus to thermal gradients, and ecological implications. Mar Ecol Prog Ser 76:13-23

Claireaux G, Couturier C, Groison AL (2006) Effect of temperature on maximum swimming speed and cost of transport in juvenile European sea bass (Dicentrarchus labrax). J Exp Biol 209:3420-3428

Compton TJ, Rijkenberg MJA, Drent J, Piersma T (2007) Thermal tolerance ranges and climate variability: a comparison between bivalves from differing climates. J Exp Mar Biol Ecol 352:200-211

Emlet RB, Sadro SS (2006) Linking stages of life history: how larval quality translates into juvenile performance for an intertidal barnacle (Balanus glandula). Integr Comp Biol 46:334-346
Epifanio CE, Garvine RW (2001) Larval transport on the Atlantic continental shelf of North America: a review. Estuar Coast Shelf Sci 52:51-77

Fagetti GE, Campodonico I (1971) Desarrollo larval en el laboratorio de Taliepus dentatus (Milne-Edwards) (Crustacea Brachyura: Majidae, Acanthocyclinae). Rev Biol Mar Valpso 14:1-14

Fangue NA, Hofmeister M, Schulte PM (2006) Intraspecific variation in thermal tolerance and heat shock protein gene expression in common killifish, Fundulus heteroclitus. J Exp Biol 209:2859-2872

Forward JRB (1990) Behavioral Responses of crustacean larvae to rates of temperature change. Biol Bull (Woods Hole) 178:195-204

Frederich M, Pörtner HO (2000) Oxygen limitation of thermal tolerance defined by cardiac and ventilatory performance in spider crab, Maja squinado. Am J Physiol Regul Integr Comp Physiol 279:R1531-R1538

Frederich M, O'Rourke MR, Furey NB, Jost JA (2009) AMPactivated protein kinase (AMPK) in the rock crab, Cancer irroratus: an early indicator of temperature stress. J Exp Biol 212:722-730

> Gardner C, Maguire GB, Williams H (2004) Effects of water temperature and thermoclines on larval behaviour and development in the giant crab Pseudocarcinus gigas (Lamarck). J Plankton Res 26:393-402

> Goss LB, Bunting DL (1976) Thermal tolerance of zooplankton. Water Res 10:387-398

> Halcrow K, Boyd CM (1967) The oxygen consumption and swimming activity of the amphipod Gammarus oceanicus at different temperatures. Comp Biochem Physiol 23: 233-242

Huey RB, Kingsolver JG (1989) Evolution of thermal sensitivity of ectotherm performance. Trends Ecol Evol 4:131-135

Jensen LD, Davies RM, Brooks AS, Meyers CD (1969) The effects of elevated temperature upon aquatic invertebrates. Report No. 4, EEI Publication 69-900. Edison Electric Institute, New York, NY

Johnston IA, Benett AF (eds) (1996) Animals and temperature: phenotypic and evolutionary adaptation. Soc Exp Biol Semin Ser 59

Kaplan DM, Largier JL, Navarrete SA, Guinez R, Castilla JC (2003) Large diurnal temperature fluctuations in the nearshore water column. Estuar Coast Shelf Sci 57: 385-398

Kaufmann R (1990) Respiratory cost of swimming in larval and juvenile cyprinids. J Exp Biol 150:343-366

Kelly P, Sulkin SD, Heukelem WF (1982) A dispersal model for larvae of the deep sea red crab Geryon quinquedens based upon behavioral regulation of vertical migration in the hatching stage. Mar Biol 72:35-43

Kuramoto M (1978) Thermal tolerance of frog embryos as a function of developmental stage. Herpetologica 34: $417-422$

Lee RW (2003) Thermal tolerances of deep-sea hydrothermal vent animals from the Northeast Pacific. Biol Bull (Woods Hole) 205:98-101

Linton TK, Morgan IJ, Walsh PJ, Wood CM (1998) Chronic exposure of rainbow trout (Oncorhynchus mykiss) to simulated climate warming and sublethal ammonia: a yearlong study of their appetite, growth, and metabolism. Can J Fish Aquat Sci 55:576-586

Mark FC, Bock C, Pörtner HO (2002) Oxygen-limited thermal tolerance in Antarctic fish investigated by MRI and 31PMRS. Am J Physiol Regul Integr Comp Physiol 283: R1254-R1262

Melzner F, Bock C, Pörtner HO (2006) Critical temperatures 
in the cephalopod Sepia officinalis investigated using in vivo ${ }^{31}$ P NMR spectroscopy. J Exp Biol 209:891-906

Morgan SG (1995) Life and death in the plankton: larval mortality and adaptation. In: McEdward L (ed) Ecology of marine invertebrate larvae. CRC Mar Sci Ser 6:279-321

O'Connor MI, Bruno JF, Gaines SD, Halpern BS, Lester SE, Kinlan BP, Weiss JM (2007) Temperature control of larval dispersal and the implications for marine ecology, evolution, and conservation. Proc Natl Acad Sci USA 104: $1266-1271$

Pardo LM, Palma AT, Prieto C, Sepulveda P, Valdivia I, Ojeda FP (2007) Processes regulating early post-settlement habitat use in a subtidal assemblage of brachyuran decapods. J Exp Mar Biol Ecol 344:10-22

Parker LM, Ross PM, O'Connor WA (2009) The effect of ocean acidification and temperature on the fertilization and embryonic development of the Sydney rock oyster Saccostrea glomerata (Gould 1859). Glob Change Biol 15: 2123-2136

Pechenik JA (1987) Environmental influences on larval survival and development. Boxwood Press, Pacific Grove, CA

Peck LS, Webb KE, Bailey DM (2004) Extreme sensitivity of biological function to temperature in Antarctic marine species. Funct Ecol 18:625-630

Pörtner HO (2001) Climate change and temperaturedependent biogeography: oxygen limitation of thermal tolerance in animals. Naturwissenschaften 88:137-146

Pörtner HO, Farrell AP (2008) Ecology. Physiology and climate change. Science 322:690-692

Pörtner HO, Knust R (2007) Climate change affects marine fishes through the oxygen limitation of thermal tolerance. Science 315:95-97

Pörtner HO, Hardewig I, Sartoris FJ, Van Dijk PLM (1998) Energetic aspects of cold adaptation: critical temperatures in metabolic, ionic and acid-base regulation? In: Pörtner HO, Playle RC (eds) Cold ocean physiology. Soc Exp Biol Sem Ser 66:88-120

Pörtner HO, Van Dijk PLM, Hardewig I, Sommer A (2000) Levels of metabolic cold adaptation: tradeoffs in eurythermal and stenothermal ectotherms. In: Davison W, Williams HC (eds) Antarctic ecosystems: models for wider ecological understanding. Caxton Press, Christchurch, p 109-122

Pörtner HO, Lucassen M, Storch D (2005) Metabolic biochemistry: its role in thermal tolerance and in the capacities of physiological and ecological function. In: Farrell A, Steffensen JF (eds) The physiology of polar fishes. Elsevier, Amsterdam, p 79-154

Pörtner HO, Farrell A, Knust R, Lannig G, Mark F, Storch D (2009) Adapting to climate change-response. Science 323:876-877

Quetin LB, Mickel TJ, Childress JJ (1978) A method for simultaneously measuring the oxygen consumption and activity of pelagic crustaceans. Comp Biochem Physiol A Physiol 59:263-266

Quinn GP, Keough MJ (2002) Experimental design and data analysis for biologists. Cambridge University Press, Cambridge

Read KR, Cumming KB (1967) Thermal tolerance of the bivalve mollusks Modiolus modiolus L., Mytilus edulis L. and Brachidontes demissus Dillwyn. Comp Biochem Physiol 22:149-155
Rodnick KJ, Gamperl AK, Lizars KR, Bennett MT, Rausch RN, Keeley ER (2004) Thermal tolerance and metabolic physiology among redband trout populations in south-eastern Oregan. J Fish Biol 64:310-335

Rumrill SS (1990) Natural mortality of marine invertebrate larvae. Ophelia 32:163-198

Stillman JH (2002) Causes and consequences of thermal tolerance limits in rocky intertidal porcelain crabs, genus Petrolistes. Integr Comp Biol 42:790-796

Shanks AL (1995) Oriented swimming by megalopae of several eastern North Pacific crab species and its potential role in their onshore migration. J Exp Mar Biol Ecol 186: $1-16$

> Somero GN (2002) Thermal physiology and vertical zonation of intertidal animals: optima, limits and costs of living. Integr Comp Biol 42:780-789

Spicer JI, Morritt D (1996) Ontogenic changes in cardiac function in Crustaceans. Comp Biochem Physiol A114:81-89

Storch D, Santelices P, Barria J, Cabeza K, Pörtner HO, Fernández M (2009) Temperature tolerance of zoea I from two different populations of the kelp crab Taliepus dentatus. J Exp Biol 212:1371-1376

Sulkin SD (1984) Behavioral basis of depth regulation in the larvae of brachyuran crabs. Mar Ecol Prog Ser 15:181-205

Swadling KM, Ritz DA, Nicol S, Osborn JE, Gurney LJ (2005) Respiration rate and cost of swimming for Antarctic krill, Euphausia superba, in large groups in the laboratory. Mar Biol 146:1169-1175

> Thorson G (1950) Reproductive and larval ecology of marine bottom invertebrates. Biol Rev Camb Philos Soc 25:1-45

Torres JJ, Childress JJ (1983) Relationship of oxygen consumption to swimming speed in Euphausia pacifica. Mar Biol 74:79-86

> Vargas CA, Narváez DA, Piñones A, Venegas RM, Navarrete SA (2004) Internal tidal bore warm fronts and settlement of invertebrates in central Chile. Estuar Coast Shelf Sci 61:603-612

Vargas CA, Escribano R, Poulet S (2006a) Phytoplankton food quality determines time windows for successful zooplankton reproductive pulses. Ecology 87:2992-2999

> Vargas CA, Manriquez PH, Navarrete SA (2006b) Feeding by larvae of intertidal invertebrates: assessing their position in pelagic food webs. Ecology 87:444-457

Vernberg FJ, Vernberg WB (1964) Metabolic adaptation of animals from different latitudes. Helgol Mar Res 9: 476-487

- Wang T, Overgaard J (2007) The heartbreak of adapting to global warming. Science 315:49-50

Weiss M, Thatje S, Heilmayer O (2010) Temperature effects on zoeal morphology and intraspecific variability in the hairy crab Cancer setosus across latitude. Helgol Mar Res 64:125-133

Wittmann AC, Schröer M, Bock C, Steeger HU, Paul RJ, Pörtner HO (2008) Indicators of oxygen-and capacity-limited thermal tolerance in the lugworm Arenicola marina. Clim Res 37:227-240

> Xu X, Ji X (2006) Ontogenetic shifts in thermal tolerance, selected body temperature and thermal dependence of food assimilation and locomotor performance in a lacertid lizard, Eremias brenchleyi. Comp Biochem Physiol A Comp Physiol 143:118-124

Submitted: March 11, 2009; Accepted: January 26, 2011

Proofs received from author(s): May 4, 2011
Editorial responsibility: Inna Sokolova,

Charlotte, North Carolina, USA 